\title{
Aktualisieren Sie Ihre Fachkunde auf dem RöKo 2016 nach Röntgenverordnung
}

Wenn in diesem Jahr Ihre Fachkunde nach §18a RöV abläuft und aktualisiert werden muss, haben wir zwei einfache Möglichkeiten für Sie. Entweder kombinieren Sie unser Onlinemodul A (am 20. oder 28.04.16) mit dem Präsenzmodul $C$ auf dem Röntgenkongress, oder Sie besuchen die komplette Präsenzaktualisierung ( $7 \mathrm{~h}$ ) auf dem RöKo. Eine Kombination der Module A und C (Modul B wird nicht benötigt; dieses bezieht sich auf StrlSchV) ergibt die komplette Aktualisierung nach RöV.

Auf dem 97. Deutschen Röntgenkongress wird die Aktualisierung nach Strahlenschutzverordnung (Modul B) nicht angeboten. Die Möglichkeit nach RöV und
StrlSchV zu aktualisieren, bietet die DRG z.B. wieder im Dezember in Fürth („Lebkuchenkongress“) an.

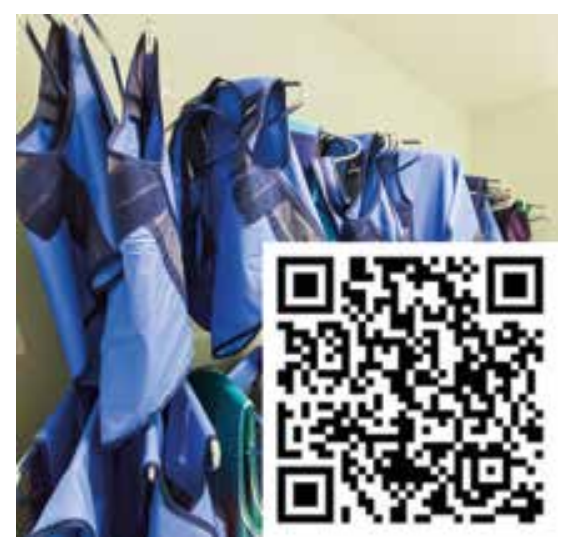

